\title{
On Being in the Wrong Place: The Role of Children's Conceptual Understanding and Ballgame Experience when Judging a Football Player's Offside Position
}

\author{
Christiane Lange-Küttner ${ }^{\mathrm{a}, *}$ and Giorgia Bosco ${ }^{\mathrm{b}}$ \\ ${ }^{a}$ London Metropolitan University, $U K$ \\ ${ }^{\mathrm{b}}$ University of Turin, Italy
}

\begin{abstract}
We investigated the role of children's conceptual understanding and ballgame experience when judging whether a football player is in an offside position, or not. In the offside position, a player takes advantage of being behind the defence line of the opposing team and just waits for the ball to arrive in order to score a goal. We explained the offside rule to 7- and 9-year-old children with a Subbuteo setup. They produced drawings of an offside position until it was correct (drawing to criterion). Thereafter, children judged whether a designated player was in an offside position in a computerized task. Like adults, also children found it easier to judge when a player was in a wrong rather than a right place. Only when including frequency of ballgame practice in the analysis it was revealed that boys were better independently of age as they judged the offside position more systematically.
\end{abstract}

Keywords

Wrong place, offside position, game rules, spatial concepts, ball game playing experience

Football, which is called soccer in the US, is a favourite outdoors rule-based game (Christidou et al., 2013). Not only young men (Helsen et al., 1998), also women (Beaudoin, 2006; Lopez, 1997; Scraton et al., 1999) and children love playing football. While for boys, but not girls, becoming a professional footballer is a top choice (Looft, 1971), a ballgame pitch is depicted by all children independently of their sex when asked to draw their schoolyard (Christidou et al., 2013). Moreover, in recent months, the British Football Association (FA) has created multiple initiatives to recruit and develop female football talent (FA, 2016b). Football is often seen as a team activity that fosters social cohesion (Smyth \& Anderson,

\footnotetext{
*Address for correspondence

Dr. Chris Lange-Küttner, London Metropolitan University, School of Psychology, 166-220 Holloway Road, London N7 8DB, England, UK. Tel.: +44 2088081691 or +44 207133 2698; E-mail: c.langekuettner@londonmet.ac.uk
}

2001; Watson \& Gibson, 1980) even when children are not players, but just football supporters (Spaaij \& Anderson, 2010).

\section{Judging the Offside Position}

The current study investigates children's understanding of the offside-rule in football (FIFA, 2015/16, Law 11 , pp. 36, 99, 102, 110-118). The offside rule is special as it forbids a player to take an unfair advantage by scoring a goal from a place behind the 'enemy' line where the defence of the opposing team is circumvented. If a footballer scores from such a wrong offside place, the resulting goal would be disallowed and would not count. Hence, we trained 7- and 9-yearold children in the offside rule and thereafter tested their judgment of the offside rule by asking them to identify whether a player is in this wrong kind of place. 
While research on the offside rule has been carried out with adults (e.g. Gilis et al., 2008; Ogilvie, 2000), this current study tests for the first time whether children can already understand the offside rule.

There is currently more research about adults and referees than children judging the offside position. Studies of real football games found a substantial amount of error obtained from live videos: In the evaluations of 200 national and world cup games, of 305 erroneous decisions, $62.2 \%$ were flag errors, that is, there was no offside, but the referee had raised the flag (false positive). There were $37.7 \%$ no-flag errors, that is, there was a player in an offside position, but the referee did not raise the flag (false negative) (Oudejans et al., 2000). This seems to be a large number of slips of attention, however, this proportion varied when just refereeing decisions in FIFA games were analysed, and more false positive $(86.6 \%)$ than false negative errors (13.4\%) occurred (Helsen et al., 2006). That is, few offside situations escaped the attention of the referees, but they did blow the whistle more often than necessary. In the current study, this was tested by having trials with a designated player who is either in an offside position (target present), or not (target absent).

\section{The Development of Spatial Representation in Children}

In short, a football pitch is a spatial expanse where players need to occupy strategic positions. Different to current belief, not just the spectators may move in crowds and can be so noisy that they disturb the referee's judgment (Nevill et al., 2002). Also primary

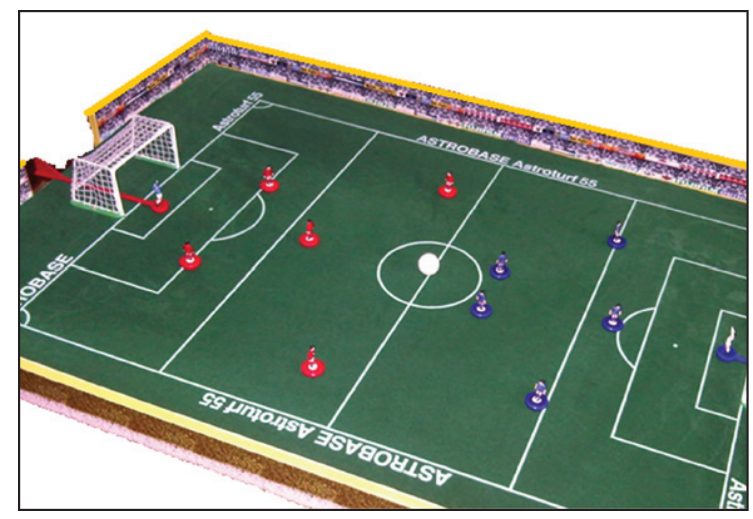

school aged players often move together across the pitch as if in a swarm which means that they cannot pass the ball towards different points on the pitch. To understand strategic positioning in the field, children need a cognitive understanding of projective space to grasp that playing in a team does not mean that you stay physically close - in talking distance - to other team members, but that you occupy a point in space to pass the ball across the field into an area where there is another free-standing team player with few opponents, who then can score from an unexpected angle. Piaget and Inhelder (1956) regarded empty space as a core notion for the understanding of spatial expanses because it involves 'decentration' from figures which occupy space (Lange-Küttner \& Reith, 1995).

Proximity is part of an early topological concept that conceptualizes space as neighbourhoods of figures, while terms such as distance and angle are part of the more advanced Euclidean concept of space. Only from about age six, children represent spatial fields with spatial axes, boundaries and vectors (Lange-Küttner, 2009, 2014). Because the development from a ground line with lined-up figures to an area where figures are distributed in the field varies considerably in children, we used a ready-made half of a football field (Lange-Küttner, 2004, 2009), see Figure 1 right, where children just had to draw the figures, but not the spatial field as such.

Young children may also draw players as tall as the whole ballgame field. The only reason for young children to reduce a players' size in a drawing is if more figures on the page use up space and hence they need to be shrunk (Lange-Küttner, 1997, 2004). However, 11-year-olds often draw top-down views and draw players particularly small (Lange-Küttner,

Figure 1. Left: Subbuteo game, Right: Drawing Sheet. The Subbuteo game was used to explain the offside rule to 7-and 9-year-old children. Children were drawing the offside position with pin men as often as required until they could create a correct depiction of the offside position. Achieving a correct drawing of the offside position was the criterion to be admitted to the offside rule computer task. 


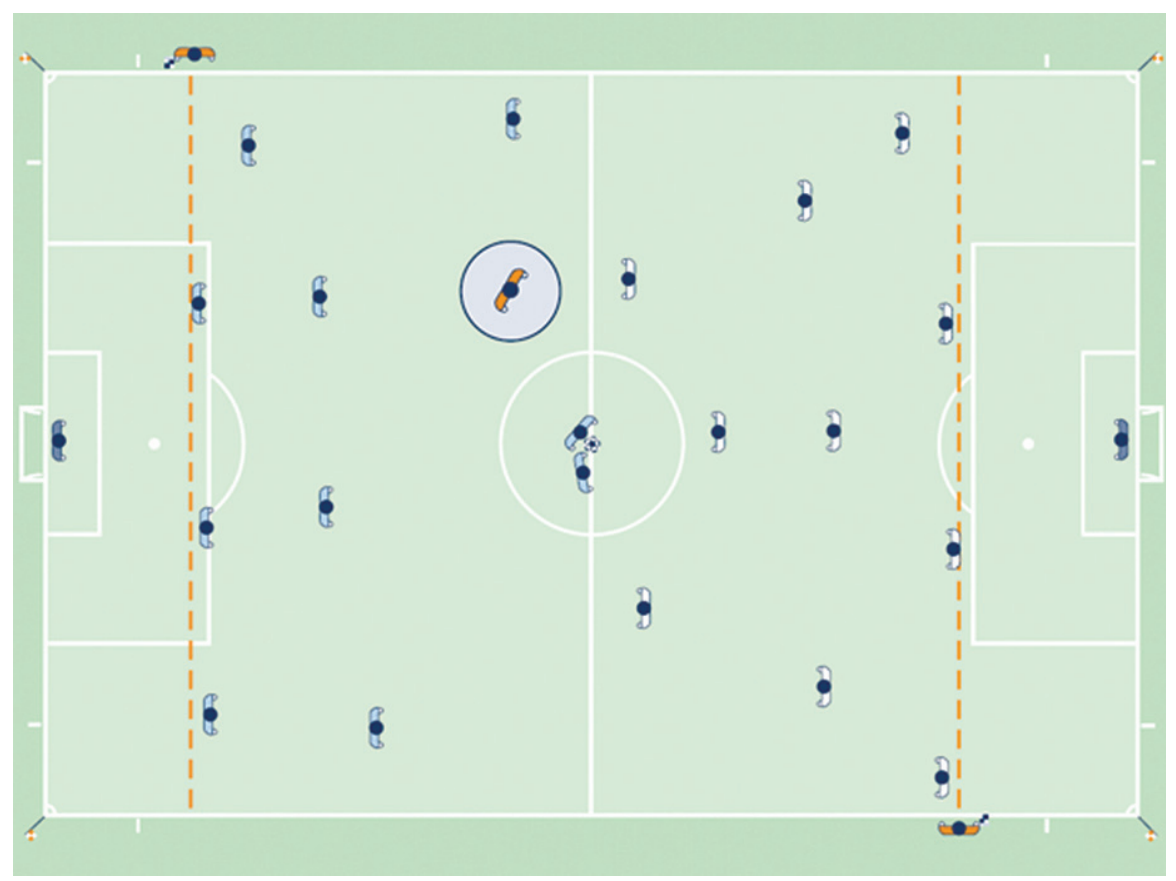

Figure 2. This drawing (reprinted with kind permission of FIFA, 2015/16, p. 77) shows broken lines which are not part of the playing field boundaries. Instead, they are imaginary projective lines that need to be made by the linesmen in order to be able to judge whether a player is before, on, or behind the defence line of the opposing players.

2009). Their representations of players have actually become very similar to those of FIFA in Figur 2: Players are depicted very small with only shoulders and head visible. The important aspect is not how they look or who they are exactly, but where they are standing in the field. Hence, we asked children to only draw the players as stick (wo)men. This top-down view is more conducive for offside judgments (Ogilvie, 2000) than the natural view of a referee (Oudejans et al., 2000).

In order to judge whether a player is in an offside position, linesmen have to create an imaginary spatial axes for the defence line-up of players of the attacked team. This line is imaginary and dynamic because it can briefly emerge and quickly disappear when the defending players align differently by running into other places in the field. In Figure 2, these projective lines are depicted in orange.

We explained the rule with a red thread in a threedimensional Subbuteo setup (Figure 1, left) and tested children's understanding of the offside position using a two-dimensional spatial field depiction (Figure 1, right). Children were drawing two teams with one football player in an offside position, until the offside position was correctly depicted. They had to achieve this as a learning criterion for being admitted to an offside-rule computer task. Also adults improve their offside position judgement with web-based training, whether on video from real-life scenes or drawings (Put et al., 2015), and both methods improved offside position judgment accuracy to the same degree.

\section{The Current Study}

The UK Football Association (FA) has a mini-soccer league and has published the FA Laws for MiniSoccer (FA, 2016a). A referee for the mini-soccer league can train from age 14. The Laws for MiniSoccer apply to children under ten years. There are several modifications to the adult game. For instance, there must be at least seven players in each team and the playing time should not exceed 60 minutes. To protect young children from becoming too competitive, there is no published league table and only three trophy events. However, fouls and misconduct are sanctioned like in adult games with free kicks and penalty kicks. There is no offside-rule in place. Hence, in the current study we investigated whether already 7- and 9-year-old children can understand and apply the offside rule when they are identifying whether a player is in a wrong place in a football field - even though they could not have had any formal teaching. Instead, we provided children this age with 


\section{Lange-Küttner and G. Bosco / Experience, Concepts, and the Off-Side Position}
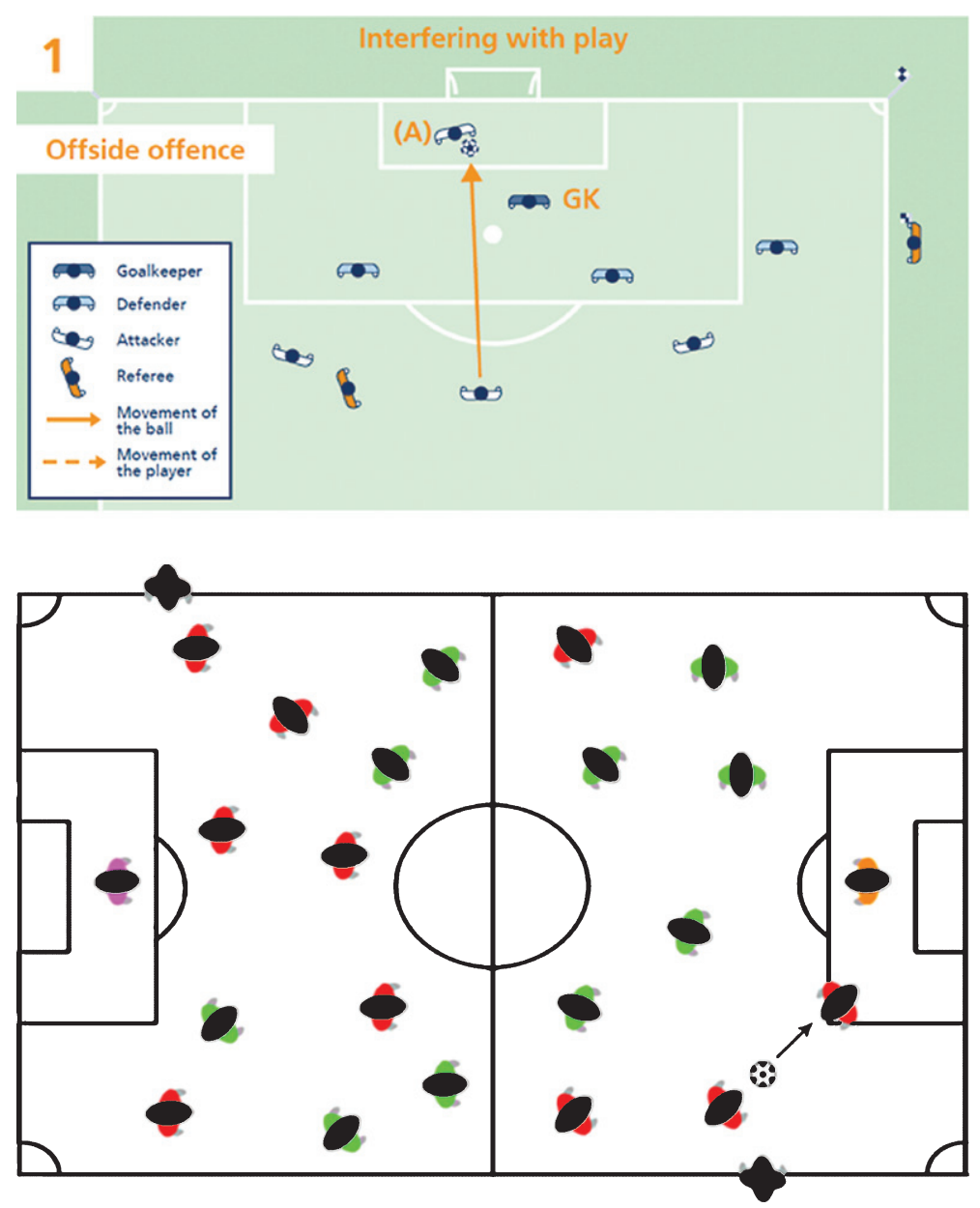

Figure 3. Top. FIFA playing field drawing (reprinted with kind permission of FIFA, 2015/16, p. 112). In the FIFA playing field, the offside player (A) in a white shirt stands behind the goal keeper (GK) and the light green (or light grey) players who are his opponents. The player $\mathrm{A}$ is in an offside position because he is played at (the arrow), but not if the ball would have gone straight into the goal, passing him by. In this case the arrow would have pointed into the goal, not at the player. Bottom. Offside Reaction Time Computer task. We adopted the arrow that points towards a player who may or may not be in an offside position. Children should either touch an offside player on the screen (48 trials), or touch the centre circle if there was no offside position (48 trials).

some training using a Subbuteo game to introduce them to the offside-rule.

We created a computerized offside position identification task similar in appearance to visual search tasks that assess the identification of a unique target amongst distracters (e.g. Donnelly et al., 2007; Remington et al., 2014; Woods et al., 2013; Zare \& Nahravanian, 2014, see Fig. 3). However, our task differs from visual search tasks insofar as the target player is easily recognizable because an arrow is pointing towards the footballer. Hence, the score was not given for finding a unique object like in a visual search task, but for identifying whether an indicated player was in a wrong place, that is, in an offside position. We predicted that reaction times in this two-step process would be longer compared to visual search tasks.

We expected to see a developmental progression towards more successful identification of the offside position in 7- and 9-year-old children because many changes occur at the same time in their spatial cognition (Lange-Küttner \& Green, 2007). Children become much better in remembering locations because they can keep track of complex spatial configurations over time (Lange-Küttner, 2010a, 2010b, 2013; Uttal et al., 2013) and they begin to represent spatial fields in their drawings (Lange-Küttner, 1997, 2004, 2009).

We also expected gender differences to emerge because boys appear to be especially good in scanning 
displays from an early age (Wilcox et al., 2012). Moreover, we controlled for underlying factors such as the experience with ballgames with a questionnaire. We assumed that children's practice was important because the gradual detachment of visual attention from figures in favour of places can be acquired without spatial concepts just by repeated visual experience (Lange-Küttner \& Küttner, 2015).

\section{Method}

\section{Design}

Identification of the offside and non-offside position was the dependent variable, assessed with repeated measures. The necessary sample size to test the main hypothesis that the older age group should be better able to identify the offside position was computed according to a 2 (age) by 2 (gender) factorial design $=4 \times 5$ (minimum cell frequency $)=20$ participants. The current sample is larger because the data collection was only stopped when all parent consent forms had been used.

\section{Participants}

Children were recruited in a primary school in the City of London. Thirty-five children were tested, but one girl dropped out during the training phase, and there was one incomplete data set. The remaining sample $N=33$ consisted of two age groups (years; months), a younger ( $n=16,7$ girls and 9 boys, $M=7 ; 5, S D=3$ months, range 85 to 94 months) and an older age group ( $n=17,6$ girls and 11 boys, $M=9 ; 5, S D=5$ months, range 105 to 118 months). According to their mean age, these age groups are labelled 7-year-olds and 9-year-olds.

\section{Materials and Procedure}

The study was approved by the departmental Ethics committee. Children's parents were informed about the aim of the research and signed a consent form to allow their children to participate. Children could withdraw from the experiment at any point in time.

The children were individually tested in a quiet classroom in the morning and early afternoon (Atkinson \& Reilly, 2012). Children first answered a questionnaire asking them if they played, liked and watched ballgames and how often. Thereafter, the second author explained the offside rule using a script. She demonstrated the offside-rule with the table game Subbuteo (see Figure 2). It was explained to each child that a player is in an offside position when (1) the player is in the opposing team's half of the football field, (2) nearer the opponents' goal line than the ball and the second last opponent, and is (3) touching the ball in action (FIFA, 2014, p. 108). The experimenter used a red thread to show the 'enemy' line behind which an offside player would need to be while waiting for the ball to come and explained that this is an imaginary line created by the line-up of players. Then demonstrations were given using the two teams of the Subbuteo game.

As soon as the explanation of the offside rule was completed, she asked the children to draw the offside position. Children drew three players of each team, the goalie for the one half-field and the referee. They were required to use four pencils: red for the defending team, green for the attacking team, black for the referee and purple for the goalkeeper. Children were allowed to just draw pin men because only their spatial positions in the field were important, but not their appearance as a figure. If the drawing was correct, the child continued with the next part of the study, the computerized experiment. If the drawing was not correct, the experimenter repeated the explanation and the child produced another drawing, and so on until the child had correctly illustrated the rule.

When a child had correctly illustrated the offside position, we assumed that he/she properly understood the rule (learning criterion), and we proceeded with the offside position judgment task. The task was presented on a Toshiba Portégé laptop, with an Intel Core i5 processor and a 12.1 inch (diagonal) touch screen, operating system Windows 7. The task was programmed using E-prime software (Psychology Software Tools, 2015). In the task the colours of the two teams were green and red, and the football field was black and white (see grey-scale Figure 3, bottom). We showed the football players in a bird-view perspective. The player in question was denoted with an arrow, and it was explained that the ball was about to be passed towards this very player.

Halfway through the task, the two teams switched the side of the field like in a real match. In $50 \%$ of the trials for each team the player was not in an offside position, and in $50 \%$ of the trials the designated player was in an offside position. There were 100 trials in total. Children first performed four practice trials, two for each team, one with and one without an offside position, followed by the remaining 96 trials. If the player was in an offside position, children touched 
the player on the screen with their index finger. If children judged that the player was not in an offside position, they touched the centre circle in the playing field see Figure 3 bottom. There was no time limit on children's responses. Once a child had touched the screen for a response, the next screen appeared.

\section{Data Generation}

We counted the numbers of drawings until the children reached the learning criterion. In total, there were 1,584 trials for the offside and 1,584 non-offside trials in the raw data sheet ( 33 participants by 48 test trials $=1,584$ trials by 2 trials types $=3,168$ trials). For accuracy, we calculated the mean accuracy in per cent and reaction times in milliseconds.

\section{Results}

Children answered the questions asking them if they played, liked and watched ballgames and how often as follows: $90.9 \%$ of the children answered that they liked ballgames while $9.1 \%$ preferred other types of sports, and $87.9 \%$ of the children said that they would watch football games. Children reported that they played on average four different types of ballgames $(M=3.65, S D=2.38$; range $1-10)$.

Children answered to the question about how often they played a ball game "more often than 3-4 times a week" (42.4\%), "1-2 times a week" (39.4\%) and "less than 2 times a month" (18.2\%). There was a significant effect of sex on this variable, $\chi^{2}(2$, $N=33)=8.80, p=0.012$. Girls played more often just 1-2 ballgames per month (girls: $38.5 \%$, boys: $5 \%$ ), while boys more often played more than 3 ballgames per week (girls: $15.4 \%$, boys: $60.0 \%$ ), but about a comparable percentage of boys and girls played 1-2 ballgames per week (girls: $46.2 \%$, boys: $35.0 \%$ ), see Figure 4 . Thus, there were more boys than girls in the sample who were very experienced in ballgames.

\section{Learning the Rule in the Subbuteo Setup}

Two thirds of the sample needed two drawings $(66.7 \%)$, three children needed one drawing $(9.1 \%)$, but eight children needed three (15.2\%) and four drawings $(9.1 \%)$. Chi-square analyses showed no significant difference between boys and girls, $p=0.163$, or age groups, $p=0.095$. The latter may have reached significance if there was a larger sample involved.
70

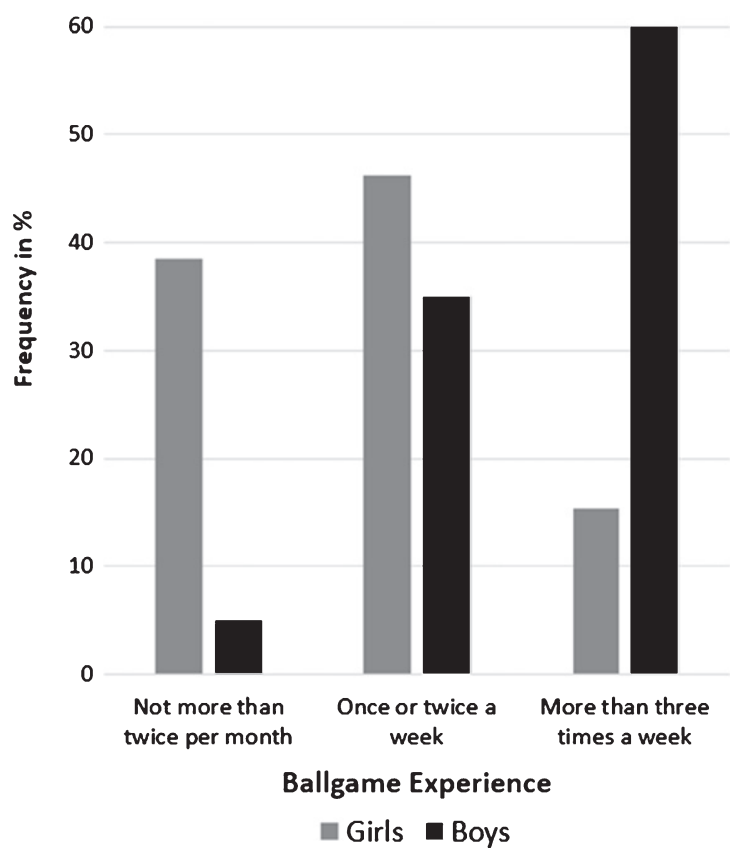

Figure 4. Sex differences in experience playing ballgames in 7and 9-year-old children: Boys play ballgames more often than girls. Frequencies add up to $100 \%$ per gender.

\section{Offside Position Judgment Task: Accuracy}

A 2 (offside/non offside) by 2 (age) by 2 (gender) ANOVA with repeated measures for offside vs. nonoffside trials was computed. Table 1 shows the group means and standard deviations for offside and the non-offside trials by age and gender. A main effect of the offside position trials was found, $F(1,33)=7.47$, $p=0.011, \eta^{2}=0.21$. Children showed significantly higher accuracy when recognizing an offside position $(M=71.6 \%)$ than judging that the player was not in an offside position $(M=62.6 \%)$. No other effect reached significance, $p_{s}>0.068$, see Table A1 (Appendix).

When the analysis was controlled with the number of drawings needed to graphically represent the offside position (learning criterion) as a covariate, the main effect of the difference between offside and non-offside judgments was no longer significant, $F(1$, 33) $=0.054, p=0.818, \eta^{2}=0.00$. This showed that the point when during the Subbuteo training the children had drawn a correct spatial configuration of an offside position also later showed in their ability to recognize an offside position better than a non-offside position in the computerized visual task. The learning criterion 
Table 1

Group Means for Accuracy and Reaction Times in Offside Rule Decision Making

\begin{tabular}{|c|c|c|c|c|c|c|c|c|c|}
\hline \multirow{3}{*}{$\begin{array}{l}\text { Age } \\
\text { Group } \\
7 \text { years }\end{array}$} & \multicolumn{5}{|c|}{ Offside Trials } & \multicolumn{4}{|c|}{ Non-Offside Trials } \\
\hline & \multirow{2}{*}{$\begin{array}{l}\text { Sex } \\
\text { Girls }\end{array}$} & \multicolumn{2}{|c|}{ Accuracy $(\%)$} & \multicolumn{2}{|c|}{ RT (ms) } & \multicolumn{2}{|c|}{ Accuracy $(\%)$} & \multicolumn{2}{|c|}{ RT (ms) } \\
\hline & & 65.47 & (19.97) & 8850 & (3559) & 61.61 & $(21.76)$ & 8550 & $(4369)$ \\
\hline & Boys & 55.56 & (16.93) & 6324 & (3351) & 69.20 & (11.63) & 6691 & (3590) \\
\hline & Total & 59.89 & (18.39) & 7429 & (3568) & 65.88 & (16.63) & 7504 & (3926) \\
\hline \multirow[t]{3}{*}{9 years } & Girls & 59.03 & (11.53) & 3791 & $(859)$ & 68.43 & (13.65) & 3647 & (834) \\
\hline & Boys & 70.46 & (19.01) & 4297 & (569) & 87.32 & (11.04) & 4144 & $(508)$ \\
\hline & Total & 66.43 & (17.29) & 4118 & (703) & 80.65 & (14.86) & 3969 & $(662)$ \\
\hline \multirow[t]{3}{*}{ Total } & Girls & 62.50 & (16.31) & 6515 & (3679) & 64.76 & (18.08) & 6287 & (4038) \\
\hline & Boys & 63.75 & (19.20) & 5209 & (2443) & 79.16 & (14.37) & 5290 & (2693) \\
\hline & Total & 63.26 & (17.86) & 5724 & (3006) & 73.49 & $(17.21)$ & 5683 & (3266) \\
\hline
\end{tabular}

Note. Standard Deviations are in brackets.

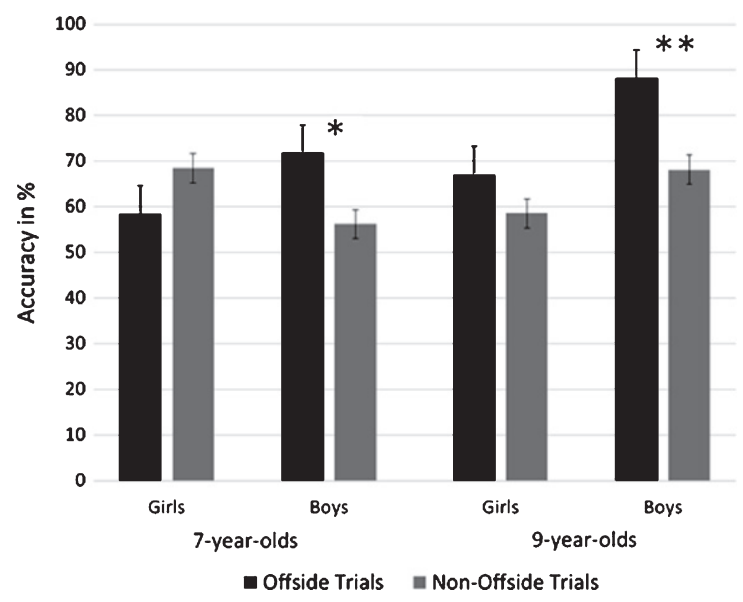

Figure 5. Only when the amount of ballgame experience was considered it showed that boys were better in making correct decisions about offside positions of designated players than girls, independently of age. Note. $*=p<0.05 ; * *=p<0.01$.

completely explained how well the positive offside position identification could be identified as the effect size was reduced from 0.21 to zero.

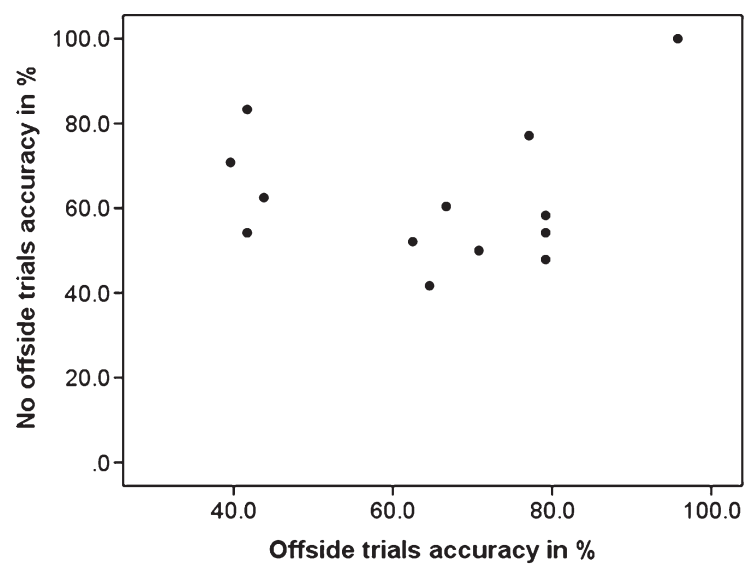

When instead the analysis was controlled for children's ballgame experience as covariate, both the significance of the offside position effect, $F(1$, 33) $=8.42, p=0.007, \eta^{2}=0.23$, and the offside position by gender effect interaction were significant, $F(2,33)=6.75, p=0.015, \eta^{2}=0.19$, see Figure 5 . Post-hoc pairwise $t$-tests (95\% confidence interval) showed that in girls, the difference between offside $(M=64.7 \%)$ and non-offside position $(M=62.5 \%)$ judgment was not significant, $t(12)=-0.36, p=0.728$ ( 7 years $p=0.716$; 9 years $p=0.234$ ). In contrast, the difference between offside $(M=79.1 \%)$ and the nonoffside position $(M=63.7 \%)$ judgment was highly significant in boys, $t(19)=-4.65, p<0.001$ (7 years $p=0.034$; 9 years $p=0.003$ ).

We also tested the scores of the complete sample as well as of boys and girls separately with one-sample $t$ tests (two-tailed) to show whether performance levels were significantly above the chance level of $50 \%$ for both offside and non-offside trials. All tests showed that the children performed better than chance, $p_{s}<$ 0.001, see Table A3 (Appendix).

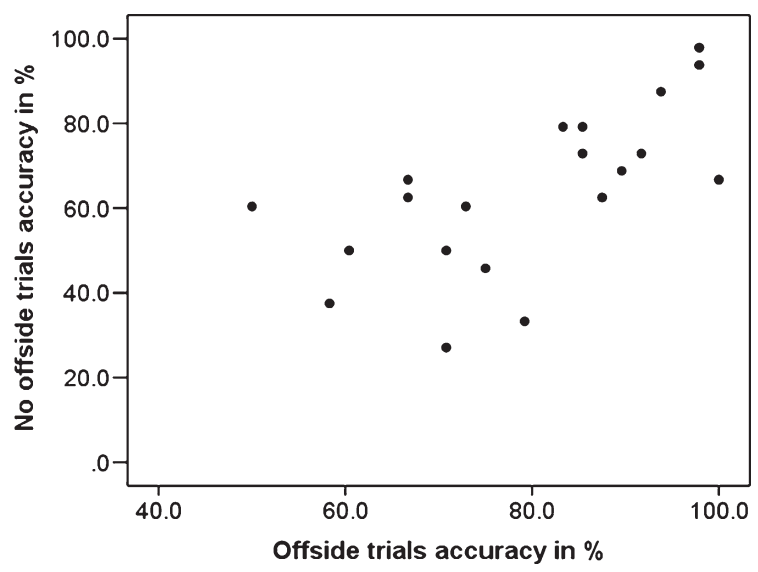

Figure 6. Scattergram for the contingency between offside and non-offside position judgment in girls (left, $r=0.11, n s$ ) and boys (right, $\left.r=0.64^{* *}\right)$. 
The two types of position judgment were not significantly correlated in girls, $r=0.11, p=0.711$, but they were significantly correlated in boys, $r=0.64$, $p=0.002$, see the scattergrams in Figure 6. Those boys who correctly recognized an offside position of a player were also more likely to identify when the player was not position offside, and vice versa. Thus, judgment of offside and non-offside positions in boys was more likely to be systematic than in girls.

In order to control the gender differences for both understanding (the learning criterion) and the ballgame experience, these were simultaneously entered as covariates. The offside position by gender interaction remained significant, $F(2,33)=6.00, p=0.021$, $\eta^{2}=0.18$. Thus, the experience of playing a ballgame on a nearly daily basis in real life was more conducive for boys than our offside rule training with the Subbuteo football game.

\section{Reaction Times}

The same analysis of variance was carried out for reaction times (see Table 1 for group means and standard deviations). The statistical effects are listed in the Appendix Table A2. A significant age effect, $F(2,33)=15.42, p<0.001, \eta^{2}=0.35$, showed that 7year-olds decided much slower $(M=7604 \mathrm{~ms})$ than 9-year-olds $(M=3970 \mathrm{~ms})$, that is a decrease in reaction times by $191.5 \%$. All other effects were not significant, $p_{s}>0.218$. When both the learning criterion and the ballgame experience were entered as covariates, the age effect was somewhat lowered but still significant, $F(2,33)=9.69, p=0.004, \eta^{2}=0.26$.

When inspecting Table 1 , we observed that the standard deviations of the reaction times were smaller in 9-year-old than in 7-year-old children indicating that their reaction time scores showed more homogeneity. Hence, the analysis of variance was re-run for the 9-year-old children only. The interaction of ballgame experience and offside/non-offside trials was now marginally significant for reaction times, $F(2$, $33)=4.51, p=0.054, \eta^{2}=0.26$. Inspection of scatterplots showed that 9-year-old children with the most practice in ballgames needed at least 3.5 seconds to decide about the offside position, while less practiced 9-year-olds made more rash decisions.

Correlations (two-tailed) between accuracy and reaction times for the offside position identification were $r=-0.47, p=0.005$ (girls $r=-0.46, p=0.116$; boys $r=-0.41, p=0.075$ ), and for the non-offside position $r=0.00, p=0.991$ (girls $r=-0.19, p=0.542$; boys $r=0.16, p=0.490$ ). Inspection of the scatterplot for the significant correlation showed that the slower the reaction times, the lower the accuracy, that is, no accuracy-reaction time trade-off could be observed.

\section{Discussion}

This is the first study that investigates understanding of the offside position rule in children and does so with a new computerized task. It is a paradigm where a social rule (you should not take an unfair advantage) is applied to a spatial configuration of players in the football field. On the one hand, the offside rule of football forbids to send a spy behind the defence line who then carries out an operation where the success is only the result of circumventing the opposing team that tries to defend their half of the spatial field. But on the other hand, there is the offside trap where defence players isolate a striker and build up a defence line behind this attacker (from the view of the goalie) so that the striker finds himself in a wrong and illegitimate position without actually having had the intention to short-cut the defence. This strategic move was already mentioned by a 9 -year-old boy.

Children showed higher accuracy when recognizing an offside position than when the player was not in an offside position, similar to adult FIFA referees (Helsen et al., 2006). Seven-year-olds' judgments were much slower $(M=7604 \mathrm{~ms})$ than in 9-year-olds ( $M=3970 \mathrm{~ms})$. However, in both age groups, these reaction times are relatively slow (Lange-Küttner, 2012). They were longer than in visual search tasks where children between 6 and 12 years do not have reaction times above $3000 \mathrm{~ms}$ (Darby et al., 2014; Merrill \& Conners, 2013). We presume that this may be the case because in order to think about the location of a figure's place, the particular figure needs to be ignored, while in a visual search task, the target is an outlier figure that just needs to attract selective attention. However, the amount of 'distracter' players in the current task was also comparably high and may have been another reason for the relatively long reaction times.

An important underlying factor in the successful identification of the offside position was the actual experience in playing ballgames. While all children had learned from our introduction with the Subbuteo game, the consideration of the action-based experiential factor revealed that boys who played ballgames several times per week showed as a group a better and more systematic approach than the girls in the present study. 
This demonstrated that boys' experience of being and acting within in a spatial field was crucial to decision-making about the offside position at age seven and nine, like in adult male-only samples (Gilis et al., 2008). Our result is in accordance with a recent study showing that football training on the ground did not only improve physical scores such as sprinting and jumping, but also a visual discrimination score which measured figure-ground perception, perceptual grouping and discrimination of detail in 7-11 year old children (Alesi et al., 2015). Moreover, in a recent study of the role of experience in the quicker game of table tennis which is played within a smaller area with a lighter ball, the acceleration of the ball in the game was the most reliable indicator of expertise and experience (Padulo et al., 2016). Hence, it may be a possibility that the visual tracking of the football in the game improves visual discrimination that benefits children and adults also in computerized assessments such as the offside rule task that we developed.

There is an ongoing debate whether spatial cognition is based on experience, or on spatial concepts (e.g. De Goede \& Postma, 2015; Hund \& Minarik, 2006; Lange-Küttner \& Küttner, 2015; Rieser \& Pick, 2007). Specifically in children, it may also be the case that the fierce competition for the football that needs to be learned by young children who often do not appreciate competitive games (Priewasser et al., 2013) acts as a mediator for tracking the position of the ball, respectively tracking who is in possession of the ball. A "caring" kindergarten approach would allocate each player a ball so that there would be no fight, but also no monitoring or search.

Thus, the current experimental study with children confirmed the general insight from adult studies on the offside rule that conceptual knowledge may need enrichment with action-based participation in the field in order to result in intelligent decisions. While our dry-run training with the Subbuteo game forged an understanding that allowed both boys and girls to discriminate between offside and non-offside position, the more frequent real-life learning-by-doing that boys reported may have sharpened their visuospatial perception.

A limitation of the current study is that game experience was not an experimental design factor. Follow-up studies may be able to include the gender factor based on specific play experience rather than just based on the biological difference between the sexes. For instance, if one recruited a select group of girls who competitively train to play women football and compared these against boys who prefer libraries over the football ground, the offside rule task may show the same effect of football game experience, but reversed in terms of gender distribution.

\section{Author Note}

We thank the Deputy Head Teacher Sue Laney, the teaching staff as well as children and their parents of the CE Sir John Cass's Foundation Primary School, London, UK, for taking part in the study. We are grateful to our technician John Hucker for guidance with the development of the E-Prime experiment, and two anonymous reviewers for their comments.

\section{References}

Alesi, M., Bianco, A., Padulo, J., Luppina, G., Petrucci, M., Paoli, A., ... \& Pepi, A. (2015). Motor and cognitive growth following a football training program. Frontiers in Psychology, 6, Article 1627. Doi: $10.3389 /$ fpsyg.2015.01627

Atkinson, G., \& Reilly, T. (2012). Circadian variation in sports performance. Sports Medicine, 21, 292-312. Doi: 10.2165/00007256-199621040-00005

Beaudoin, C. M. (2006). Competitive orientations and sport motivation of professional women football players: An internet survey. Journal of Sport Behavior, 29, 201-212.

Christidou, V., Tsevreni, I., Epitropou, M., \& Kittas, C. (2013). Exploring primary children's views and experiences of the school ground: The case of a Greek school. International Journal of Environmental and Science Education, 8, 59-83.

Darby, K. P., Burling, J. M., \& Yoshida, H. (2014). The role of search speed in the contextual cueing of children's attention. Cognitive Development, 29, 17-29. Doi: 10.1016/j.cogdev.2013.10.001

De Goede, M., \& Postma, A. (2015). Learning your way in a city: Experience and gender differences in configurational knowledge of one's environment. Frontiers in Psychology, 6. Article 402. Doi: $10.3389 /$ fpsyg. 2015.00402

Donnelly, N., Cave, K., Greenway, R., Hadwin, J. A., Stevenson, J., \& Sonuga-Barke, E. (2007). Visual search in children and adults: Top-down and bottom-up mechanisms. The Quarterly Journal of Experimental Psychology, 60, 120-136. Doi: $10.1080 / 17470210600625362$

FA (2016a). The Football Association Laws for Mini-Soccer. London: The Football Association.

FA (2016b). Girls' England talent pathway. Retrieved from http://www.thefa.com/womens-girls-football/england-talentpathway

FIFA (2014). The laws of the game. Zurich: Fédération Internationale de Football Association.

FIFA (2015/16). The laws of the game. Zurich: Fédération Internationale de Football Association.

Gilis, B., Helsen, W., Catteeuw, P., \& Wagemans, J. (2008). Offside decisions by expert assistant referees in association football: Perception and recall of spatial positions in complex dynamic 
events. Journal of Experimental Psychology: Applied, 14, 2135. Doi: 10.1037/1076-898X.14.1.21

Helsen, W. F., Gilis, B., \& Weston, M. (2006). Errors in judging 'offside' in association football: Test of the optical error versus the perceptual flash-lag hypothesis. Journal of Sports Sciences, 24, 521-528. Doi: 10.1080/02640410500298065

Helsen, W. F., Starkes, J. L., \& Hodges, N. J. (1998). Team sports and the theory of deliberate practice. Journal of Sport \& Exercise Psychology, 20, 12-34

Hund, A. M., \& Minarik, J. L. (2006). Getting from here to there: Spatial anxiety, wayfinding strategies, direction type, and wayfinding efficiency. Spatial Cognition and Computation, 6, 179-201. Doi: 10.1207/s15427633scc0603_1

Lange-Küttner, C. (1997). Development of size modification of human figure drawings in spatial axes systems of varying complexity. Journal of Experimental Child Psychology, 66, 264-278. Doi: 10.1006/jecp.1997.2386

Lange-Küttner, C. (2004). More evidence on size modification in spatial axes systems of varying complexity. Journal of Experimental Child Psychology, 88, 171-192. Doi: 10.1016/j.jecp.2004.02.003

Lange-Küttner, C. (2009). Habitual size and projective size: The logic of spatial systems in children's drawings. Developmental Psychology, 45, 913-927. Doi: 10.1037/a0016133

Lange-Küttner, C. (2010a). Gender-specific developmental pathways for boys and girls: The Wertheimer CommonRegion-Test can predict spatial memory. European Journal of Developmental Science, 4, 46-66. Doi: 10.3233/DEV-20104104

Lange-Küttner, C. (2010b). Ready-made and self-made facilitation effects of arrays: Priming and conceptualization in children's visual memory. Swiss Journal of Psychology, 69, 189-200. Doi: 10.1024/1421-0185/a000023

Lange-Küttner, C. (2012). The importance of reaction times for Developmental Science: What a difference milliseconds make. International Journal of Developmental Science, 6, 51-55. Doi: 10.3233/DEV-2012-11089

Lange-Küttner, C. (2013). Array effects, spatial concepts, or information processing speed: What is the crucial variable for place learning? Swiss Journal of Psychology, 72, 197-217. Doi: 10.1024/1421-0185/a000113

Lange-Küttner, C. (2014). Do drawing stages really exist? Children's early mapping of perspective. Psychology of Aesthetics, Creativity, and the Arts, 8, 168-182. Doi: 10.1037/a0036199

Lange-Küttner, C., \& Green, H. (2007). What is the age of mental rotation? Proceedings of the 6th IEEE International Conference on Development and Learning (pp. 259-263): IEEE Press.

Lange-Küttner, C., \& Küttner, E. (2015). How to learn places without spatial concepts: Does the what-and-where reaction time system in children regulate learning during stimulus repetition? Brain and Cognition, 97, 59-73. Doi: 0.1016/j.bandc.2015.04.008

Lange-Küttner, C., \& Reith, E. (1995). The transformation of figurative thought: Implications of Piaget and Inhelder's developmental theory for children's drawings. In C. Lange-Küttner \& G. V. Thomas (Eds.), Drawing and looking (pp. 75-92). Hemel Hampstead: Harvester Wheatheaf/Pearson.

Looft, W. R. (1971). Sex differences in the expression of vocational aspirations by elementary school children. Developmental Psychology, 5, 366. Doi: 10.1037/h0031432

Lopez, S. (1997). Women on the ball: A guide to women's football. London: Scarlet.
Merrill, E. C., \& Conners, F. A. (2013). Age-related interference from irrelevant distracters in visual feature search among heterogeneous distracters. Journal of Experimental Child Psychology, 115, 640-654. Doi: 10.1016/j.jecp.2013.03.013

Nevill, A. M., Balmer, N. J., \& Williams, A. M. (2002). The influence of crowd noise and experience upon refereeing decisions in football. Psychology of Sport and Exercise, 3, 261-272. Doi: 10.1016/S1469-0292(01)00033-4

Ogilvie, J. (2000). Inside, outside, offside? Trends in Cognitive Sciences, 4, 130. Doi: 10.1016/S1364-6613(00)01480-7

Oudejans, R. R., Verheijen, R., Bakker, F. C., Gerrits, J. C., Steinbrückner, M., \& Beek, P. J. (2000). Errors in judging 'offside'in football. Nature, 404(6773), 33. Doi: $10.1038 / 35003639$

Padulo, J., Pizzolato, F., Tosi Rodrigues, S., Migliaccio, G. M., Attene, G., Curcio, R., \& Zagatto, A. M. (2016). Task complexity reveals expertise of table tennis players. The Journal of Sports Medicine and Physical Fitness, 56, 149-156

Piaget, J., \& Inhelder, B. (1956). The child's conception of space. London: Routledge and Kegan Paul.

Priewasser, B., Roessler, J., \& Perner, J. (2013). Competition as rational action: Why young children cannot appreciate competitive games. Journal of Experimental Child Psychology, 116, 545-559. Doi: 10.1016/j.jecp.2012.10.008

Psychology Software Tools (2015). EPrime (Version 2.0). Sharpsburg, PA: Psychology Software Tools. Retrieved from http://www.pstnet.com/eprime.cfm

Put, K., Wagemans, J., Spitz, J., Williams, A. M., \& Helsen, W. F. (2015). Using web-based training to enhance perceptual-cognitive skills in complex dynamic offside events. Journal of Sports Sciences, 34, 181-189. Doi: 10.1080/02640414.2015.1045926

Remington, A., Cartwright-Finch, U., \& Lavie, N. (2014). I can see clearly now: The effects of age and perceptual load on inattentional blindness. Frontiers in Human Neuroscience, 8. Doi: 10.3389/fnhum.2014.00229

Rieser, J. R., \& Pick, H. L. (2007). Using locomotion to update spatial orientation. In J. Plumert \& J. P. Spencer (Eds.), The emerging spatial mind (pp. 77-103). Oxford: Oxford University Press.

Scraton, S., Fasting, K., Pfister, G., \& Bunuel, A. (1999). It's still a man's game? The experiences of top-level European women footballers. International Review for the Sociology of Sport, 34, 99-111.

Smyth, M. M., \& Anderson, H. I. (2001). Football participation in the primary school playground: The role of coordination impairments. British Journal of Developmental Psychology, 19, 369-379. Doi: 10.1348/026151001166155

Spaaij, R., \& Anderson, A. (2010). Psychosocial influences on children's identification with sports teams: A case study of Australian Rules football supporters. Journal of Sociology, 46, 299-315. Doi: 10.1177/1440783310371403

Uttal, D. H., Meadow, N. G., Tipton, E., Hand, L. L., Alden, A. R., Warren, C., \& Newcombe, N. S. (2013). The malleability of spatial skills: A meta-analysis of training studies. Psychological Bulletin, 139, 352-402. Doi: 10.1037/a0028446

Watson, G. G., \& Gibson, B. J. (1980). Determinants of social integration in children's sport teams: The case of Australian rules football. International Journal of Sport Psychology, 11, 75-90.

Wilcox, T., Alexander, G. M., Wheeler, L., \& Norvell, J. M. (2012). Sex differences during visual scanning of occlusion events 
in infants. Developmental Psychology, 48, 1091-1105. Doi: $10.1037 / \mathrm{a} 0026529$

Woods, A. J., Göksun, T., Chatterjee, A., Zelonis, S., Mehta, A., \& Smith, S. E. (2013). The development of organized visual search. Acta Psychologica, 143, 191-199. Doi: 10.1016/j.actpsy.2013.03.008

Zare, H., \& Nahravanian, P. (2014). The effect of training on visual search and vigilance of adult and children. Advances in Cognitive Science, 15, 9-18. Doi: 10.3389/fnhum.2014.00229

\section{Bio Sketches}

Christiane Lange-Küttner, PhD Max Planck Institute for Human Development, Berlin. Post-doc Research Fellow 1993-94 Cognitive Science Lab, Dept. of
Experimental Psychology, Freie Universität Berlin; Academic faculty 1994-99 Dept. of Psychology, University of Aberdeen, 1999- Dept. of Psychology, London Metropolitan University. 2008-2015 Privatdozentin Universität Bremen, 2009-11 Professor Developmental Psychology, Universität Konstanz. 2014 Honorary Associate Professor, University of Nicosia, Cyprus. Research on visuo-spatial cognition in searching, drawing, reading and memory as well as on learning with and without repetition under deterministic and stochastic feedback conditions.

Giorgia Bosco, 2015 MSc. in Psychology, University of Turin. 2014-2015 Intern student at the London Metropolitan University. 
C. Lange-Küttner and G. Bosco / Experience, Concepts, and the Off-Side Position

\section{APPENDIX}

Table A1

Statistical Effects: Accuracy Off-side Judgment

\begin{tabular}{|c|c|c|c|c|c|}
\hline Factor & $S S$ & $d f$ & $F$ & $p$ & eta \\
\hline \multicolumn{6}{|c|}{ Within-subject effects } \\
\hline Offside & 1269.70 & $\mathbf{1}$ & $\mathbf{7 . 4 7}$ & 0.011 & 0.21 \\
\hline Offside by Age Group & 265.05 & 1 & 1.56 & 0.222 & 0.05 \\
\hline Offside by Gender & 608.75 & 1 & 3.58 & 0.068 & 0.11 \\
\hline Offside by Age Group by Gender & 98.67 & 1 & 0.58 & 0.452 & 0.02 \\
\hline \multicolumn{6}{|c|}{ Between-subject effects } \\
\hline Age Group & 1090.86 & 1 & 3.13 & 0.087 & 0.10 \\
\hline Gender & 765.49 & 1 & 2.20 & 0.149 & 0.07 \\
\hline Age Group by Gender & 1041.67 & 1 & 2.99 & 0.095 & 0.09 \\
\hline
\end{tabular}

Note. Significant effects are set in bold.

Table A2

Statistical Effects: Reaction Times Off-side Judgment

\begin{tabular}{|c|c|c|c|c|c|}
\hline Factor & SS & $d f$ & $F$ & $p$ & eta \\
\hline \multicolumn{6}{|c|}{ Within-subject effects } \\
\hline Offside & 51721.07 & 1 & 0.18 & 0.671 & 0.01 \\
\hline Offside by Age Group & 128869.76 & 1 & 0.46 & 0.504 & 0.02 \\
\hline Offside by Gender & 423254.29 & 1 & 1.50 & 0.230 & 0.05 \\
\hline Offside by Age Group by Gender & 446899.50 & 1 & 1.59 & 0.218 & 0.05 \\
\hline \multicolumn{6}{|c|}{ Between-subject effects } \\
\hline Age Group & 206525677.90 & 1 & 15.42 & 0.000 & 0.35 \\
\hline Gender & 11180401.31 & 1 & 0.84 & 0.368 & 0.03 \\
\hline Age Group by Gender & 1041.67 & 1 & 2.12 & 0.156 & 0.07 \\
\hline
\end{tabular}

Note. Significant effects are set in bold.

Table A3

Statistical Effects: One Sample t-tests against 50\% Chance Performance (Accuracy in \%)

\begin{tabular}{|c|c|c|c|c|c|c|}
\hline \multicolumn{7}{|c|}{ One-Sample Tests (two-tailed), Test Value $=50$} \\
\hline & \multirow[b]{2}{*}{$t$} & \multirow[b]{2}{*}{$d f$} & \multirow[b]{2}{*}{$p$} & \multirow[b]{2}{*}{$M$ Difference } & \multicolumn{2}{|c|}{$95 \% \mathrm{CI}$ of the Difference } \\
\hline & & & & & Lower & Upper \\
\hline \multicolumn{7}{|c|}{ Total sample $(N=33)$} \\
\hline offside trials & -10.235 & 32 & 0.000 & -14.727 & -17.66 & -11.80 \\
\hline no offside & -13.159 & 32 & 0.000 & -19.636 & -22.68 & -16.60 \\
\hline \multicolumn{7}{|c|}{ Girls $(n=13)$} \\
\hline offside trials & -7.857 & 12 & 0.000 & -18.923 & -24.17 & -13.68 \\
\hline no offside & -9.208 & 12 & 0.000 & -20.000 & -24.73 & -15.27 \\
\hline \multicolumn{7}{|c|}{ Boys $(n=20)$} \\
\hline offside trials & -7.780 & 19 & 0.000 & -12.000 & -15.23 & -8.77 \\
\hline no offside & -9.417 & 19 & 0.000 & -19.400 & -23.71 & -15.09 \\
\hline
\end{tabular}

